\title{
Conselho Estadual de Educação do Rio de Janeiro: heranças, marcos legais e limites políticos de um órgão do Estado
}

\author{
Maria Celi Chaves Vasconcelos a \\ Nival Nunes Almeida b \\ Leonardo Ferreira Peixoto ${ }^{c}$
}

\section{Resumo}

O presente estudo tem como foco analisar a trajetória do Conselho Estadual de Educação do Rio de Janeiro (CEE/RJ), particularmente, as "heranças" e influências dos colegiados que o originaram, e os marcos legais que tiveram maior impacto sobre sua história, em uma demarcação temporal que vai desde o primeiro ordenamento jurídico de sua criação, o Decreto-Lei ${ }^{\circ} 51 / 1975$, até a Lei $n^{\circ} 6.864 / 2014$, que o torna órgão de Estado. Em um plano mais específico, evidenciam-se as implicações que as mudanças governamentais produziram no colegiado, protagonizadas pelos atores do contexto político em que o CEE/RJ estava inserido. Trata-se de uma pesquisa bibliográfica e essencialmente documental que demonstra, com subsídio das fontes, como o CEE/RJ foi marcado pela descontinuidade na política, tendo como consequência que a condição de órgão de Estado seja quase imperceptível no cotidiano e nas proposições do colegiado que, hoje, normatizam a educação fluminense. Palavras-chave: Conselho Estadual de Educação. Órgão de Estado. Políticas educacionais. Rio de Janeiro.

\section{Introdução}

Em um final de tarde, no dia 28 de abril de 1975, no palácio Guanabara, com a presença do governador do Estado, o almirante Floriano Peixoto Faria Lima,

\footnotetext{
a Universidade do Estado do Rio de Janeiro - UERJ, Programa de Pós-graduação em Educação. Rio de Janeiro, Rio de Janeiro, Brasil.

b Escola de Guerra Naval da Marinha do Brasil - EGN/MB, Programa de Pós-graduação em Estudos Marítimos - PPGEM/EGN. Rio de Janeiro, Rio de Janeiro, Brasil.

Universidade do Estado do Amazonas - UEA. Manaus, Amazonas, Brasil.
} 
e da secretária de Estado de Educação e Cultura, Myrthes de Luca Wenzel, tomavam posse os primeiros conselheiros do recém-criado Conselho Estadual de Educação, do também nascente Estado do Rio de Janeiro, após a Fusão ${ }^{1}$. Além do governador e da secretária de Educação, a solenidade contava com a presença de muitas outras "autoridades", entre elas os próprios conselheiros que seriam empossados, boa parte deles já conhecidos personagens da educação, naquele momento histórico, bem como alguns oriundos dos dois Conselhos de Educação anteriores que se desfaziam para dar origem ao novo, o do antigo Estado do Rio de Janeiro e o do Estado da Guanabara.

Com um discurso daquela que seria a presidente do órgão recém-criado, a professora Edília Coelho Garcia, escolhida pelos pares para representá-los, fazia uma preleção que exaltava os novos tempos que se iniciavam e afirmava ao governador que caberia a cada escolhido "o dever de se colocar à altura da missão, correspondendo ao crédito de confiança" (RIO DE JANEIRO, 2015, p. 13). Era um colegiado que, segundo a oradora, reunia "educadores experimentados" e "educadores bem jovens", simbolizando a própria "velha Província fluminense que renasce, madura e jovem" (Idem).

Passadas quatro décadas da primeira posse registrada detalhadamente na Ata Histórica daquela sessão solene (RIO DE JANEIRO, 2015), no dia 9 de agosto do ano de 2016, em uma manhã de terça-feira, igual a todas as outras da rotina de trabalho do Conselho Estadual de Educação do Rio de Janeiro (CEE/RJ), não mais na imponente sala de sessões que o órgão ocupava no décimo andar do edifício da Rua Erasmo Braga, $\mathrm{n}^{\circ} 118$, mas em uma sala improvisada, tanto para abrigar os pesados móveis da plenária histórica desfeita, como para permitir espaço a uma diminuta assistência composta somente por funcionários, ocorria a posse de boa parte dos conselheiros - para um mandato de quatro anos, até 2020 -, especialmente, aqueles indicados e nomeados pelo governador em exercício, Francisco Dornelles, em substituição aos que terminavam os mandatos que, por vezes, haviam durado os oito anos permitidos por lei.

Em um aparente contraste entre a monumentalização dos móveis e a condição imaterial da informalidade da sessão, de seu espaço, de seu simbolismo e da divulgação do que estava ocorrendo naquele momento, entre tantos outros sinais de desprestígio, tornava-se imperioso, ao expectador, voltar no tempo e pensar onde, quando e como, a trajetória desse colegiado levou-o à representação de apenas mais um órgão da burocracia estatal, na contramão de seu tão esperado

De acordo com Ferreira (2006, p. 163), "A fusão do estado da Guanabara com o estado do Rio de Janeiro foi decretada pelo presidente Ernesto Geisel em 12 de julho de 1974, pela Lei Complementar n²0, e implantada a partir de $1^{\circ}$ de março de $1975^{\prime \prime}$. 
"avanço", ocorrido há apenas dois anos, quando foi elevado à categoria de "órgão de Estado", pela Lei no 6.864 de 15 de agosto de 2014 (RIO DE JANEIRO, 2014).

Na referida legislação, o artigo $5^{\circ}$ alterava o $9^{\circ}$ da Lei ${ }^{\circ} 4.528$, de 28 de março de 2005, a chamada Lei do Sistema de Ensino Estadual, dando ao CEE/RJ a seguinte natureza jurídica e administrativa:

O Conselho Estadual de Educação é um órgão de Estado autônomo, normativo, regulador, consultivo e deliberativo composto de 24 (vinte e quatro) conselheiros possuidores de notável saber na área educacional ou que tenham prestado relevantes serviços à educação, indicados pelo Poder Executivo, Poder Legislativo e entidades representativas da educação, garantida a paridade entre estes, para mandato de 4 (quatro) anos e a cada 2 (dois) anos renova-se um terço, sendo permitida uma única recondução por igual período, dotado de unidade orçamentária e com quadro de pessoal próprio (RIO DE JANEIRO, 2014, Art. $5^{\circ}$ ).

Contudo, os esforços do legislador não foram suficientes para alterar substancialmente o cotidiano do colegiado nos anos subsequentes a essa legislação, excetuando-se o aumento do número de conselheiros, estando, ainda em 2017, o CEE/RJ regido pelo mesmo Regimento ${ }^{2}$, instituído pela Resolução da Secretaria de Estado de Educação, n 1.348 de 7 de outubro de 1986 (RIO DE JANEIRO, 1986), conservando a maioria das práticas nele descritas, ressalvando-se a atualização das denominações dos níveis e modalidades de ensino, a partir da Lei de Diretrizes e Bases da Educação Nacional (LDBEN), Lei n ${ }^{\circ}$ 9.394, de 20 de dezembro de 1996 (BRASIL, 1996).

Embora não fosse esperado que a simples determinação legal pudesse modificar a realidade e as práticas consolidadas há décadas, constata-se que o ritmo de adequação à legislação vigente se revelou extremamente lento. Assim, para entender como mudanças e resistências se processaram sob uma abordagem política, é preciso recorrer aos marcos legais estabelecidos para este órgão e suas implicações sobre os sujeitos e as instituições a ele subordinados.

Nessa perspectiva, o presente estudo tem como foco analisar parte da trajetória do CEE/RJ, particularmente as "heranças" e influências dos colegiados que o originaram, e os ordenamentos jurídicos que tiveram maior impacto sobre sua história, em uma demarcação temporal que se estende desde a criação pelo

Em 23 de maio de 2017; o Conselho Pleno do CEE/RJ aprovou em plenária o seu novo Regimento, encaminhando-o, a seguir, para a publicação no Diário Oficial do Estado do Rio de Janeiro. 
Decreto-Lei n ${ }^{\circ}$ 51, datado de 3 de abril de 1975 (RIO DE JANEIRO, 1975), até a Lei que altera sua condição para torná-lo órgão de Estado, em 15 de agosto de 2014. De acordo com Ozga (2000, p. 203), "uma maneira de analisarmos isto, é olharmos para a história das políticas educativas e para a narrativa explicativa que acompanha e que nos é fornecida pela investigação em política".

No percurso da pesquisa documental para a escrita deste estudo, demonstra-se, com subsídio das fontes, que as mudanças legais ocorridas ao longo das quatro décadas de existência do $\mathrm{CEE} / \mathrm{RJ}$ foram imprimindo uma marca no colegiado relacionada sobretudo à falta de autonomia, visualizando-se uma linha descendente de atuação e representatividade, em que pese a permanência de suas funções como extremamente significativas para a normatização da educação pública e privada no Estado do Rio de Janeiro.

Com todas as dificuldades e limites enfrentados em sua trajetória, o CEE/RJ, ainda hoje, desempenha um importante papel, seja como órgão recursal, seja como instância de autorização, reconhecimento e renovação de reconhecimento de cursos superiores pertencentes ao sistema estadual de ensino, além do atendimento a centenas de processos dos mais variados pleitos no campo da educação fluminense.

Nessa linha, o artigo apresentado está pautado em tópicos que tratam da legislação referente ao $\mathrm{CEE} / \mathrm{RJ}$ e as implicações que as mudanças governamentais produziram neste colegiado, confrontadas às práticas instituintes, forjadas pelos atores que fizeram parte do protagonismo e do cenário em cada período estudado, desde a origem as mais recentes tentativas de sua consolidação como órgão de Estado.

\section{Entre as reminiscências dos antigos Estados surge um novo Conselho}

O Decreto-Lei ${ }^{\circ}$ 51/1975, em seu artigo 14, conferia ao novo Conselho a sucessão dos órgãos normativos extintos: "O Conselho Estadual de Educação do Rio de Janeiro, criado por este Decreto-Lei, sucede para todos os efeitos legais, os Conselhos Estaduais de Educação integrantes da estrutura administrativa dos antigos Estados do Rio de Janeiro e da Guanabara" (RIO DE JANEIRO, 1975). Além disso, o CEE/RJ era definido como órgão responsável pela regulamentação do poder público estadual em matéria doutrinária, de caráter normativo, consultivo e de planejamento setorial ligado a assuntos educacionais.

No momento da criação do CEE/RJ, em 1975, sua natureza, finalidade e composição, como o próprio Decreto-Lei informava, remetiam a outros dois Conselhos, o do 
antigo Estado do Rio de Janeiro e o do Estado da Guanabara, instituídos a partir de 1962 e atuantes até o encerramento de suas atividades, no processo de fusão dos dois entes federados, quando os Conselhos existentes foram extintos.

$\mathrm{O} \mathrm{CEE} / \mathrm{RJ}$, criado em meio às mudanças políticas e administrativas decorrentes da nova conformação dos entes federados estabelecida a partir de 15 de março de $1975^{3}$, não poderia ser considerado "novo", mesmo para um período marcado por transformações, que iam desde os limites geográficos, até a ressignificação do pertencimento a um e outro Estado. Ao contrário, tratava-se de um órgão que, em sua estrutura, conservava as características de seus predecessores, não apenas nos ritos e procedimentos, mas também na composição que continha alguns membros já participantes dos colegiados anteriores, dando a impressão que havia dificuldades, excetuando-se os integrantes do grupo que já compunha os antigos Conselhos ou ligado às lideranças dos setores educacionais públicos e privados, para atender ao estabelecido no artigo $3^{\circ}$ do Decreto-Lei $n^{\circ} 51 / 1975$, que determinava que os conselheiros fossem "escolhidos entre pessoas de notável saber e experiência em matéria de Educação, que representem os diversos graus de ensino, o magistério oficial e o particular" (RIO DE JANEIRO, 1975).

Com efeito, foram os Conselhos dos Estados extintos que funcionavam desde 1962, que forneceram os fundamentos de criação do novo colegiado, permitindo identificar a influência que se impôs na estruturação do órgão que se constituiu no pós-fusão, incluindo-se as respectivas competências relativas à educação nos territórios sob cada jurisdição que, reunidas, tornaram o novo órgão ainda mais abrangente.

O Conselho Estadual de Educação do antigo Estado do Rio de Janeiro foi criado por ato do então governador, Celso Peçanha, em "obediência" à Lei Diretrizes e Bases da Educação Nacional (LDB), no 4.024, de 20 de dezembro de $1961^{4}$ (BRASIL, 1961), e à Lei Estadual n ${ }^{\circ}$ 5.044, de 7 de março de 1962 (RIO DE JANEIRO, 1962), que estabelecia as Diretrizes e Bases Estaduais da Educação. Este colegiado era composto por 21 membros nomeados pelo governador do Estado, com mandatos diferenciados entre seis, quatro e dois anos, "dentre pessoas de notável saber e experiência em matéria de Educação". As atribuições também eram

Decreto-Lei n 1, de 15 de março de 1975: "Art. $1^{\circ} \mathrm{O}$ Estado do Rio de Janeiro exercerá em seu território, correspondente aos dos antigos Estados da Guanabara e do Rio de Janeiro, todos os poderes que não lhe sejam vedados, implícita ou explicitamente, pela Constituição da República Federativa do Brasil".

${ }^{4}$ Lei № 4.024, de 20 de dezembro de 1961: "Art. 10 Os Conselhos Estaduais de Educação organizados pelas leis estaduais, que se constituírem com membros nomeados pela autoridade competente, incluindo representantes dos diversos graus de ensino e do magistério oficial e particular, de notório saber e experiência, em matéria de educação, exercerão as atribuições que esta lei Ihes consigna". 
definidas na Lei ${ }^{\circ}$ 5.044/1962, abrangendo um extenso leque de possibilidades, entre as quais estava previsto decidir sobre o funcionamento de instituições do ensino primário e médio estaduais, municipais e particulares, bem como "opinar sobre as de nível superior", fixar disciplinas obrigatórias para o ensino primário e completar as do Ensino Médio, além de analisar, anualmente, as estatísticas do ensino no Estado e seus dados complementares. Os conselheiros eram divididos em câmaras, para deliberarem sobre assuntos pertinentes aos diversos graus e ramos do ensino, reunindo-se em sessão plenária para analisar matérias de caráter geral. Do seu surgimento em 1962, até a extinção em 1975, o Conselho Estadual de Educação do antigo Estado do Rio de Janeiro desempenhou funções bastante significativas como se verifica no disposto na Lei ${ }^{\circ}$ 5.044/1962 (RIO DE JANEIRO, 1962) e, embora sofrendo diversas alterações na sua composição, câmaras, e até funções, ao longo dos 13 anos de sua existência, era a instância máxima de regulamentação da educação no antigo Estado do Rio de Janeiro.

$\mathrm{Na}$ origem do CEE/RJ, as demais funções que foram abarcadas pertenciam ao também extinto Conselho Estadual de Educação da Guanabara (CEE/GB), criado pela Lei Estadual n 151, de 13 de julho de 1962 (GUANABARA, 1962), da qual eram signatários o governador Carlos Lacerda e seu secretário de Educação, Carlos Octávio Flexa Ribeiro, cumprindo o disposto no artigo 55 da Constituição do Estado da Guanabara, aprovada em 27 de março de 1961 (GUANABARA, 1961), que instituía o Conselho Estadual de Educação, como dispunha a LDB de 1961. A Lei n ${ }^{\circ}$ 151/1962 que criava o Conselho Estadual de Educação da Guanabara era iniciada informando a composição de 12 membros, todos nomeados pelo governador, "dentre pessoas de notável saber e experiência em matéria de educação que representem os diversos graus de ensino e o magistério oficial e o particular" (GUANABARA, 1962, Art. $2^{\circ}$ ), um terço para o mandato de dois anos, a fim de garantir a continuidade do funcionamento, e os demais para o mandato de quatro anos, admitida uma recondução. A presidência do CEE/GB ficava a cargo do secretário de Estado de Educação e Cultura, como membro nato.

A influência da lei de criação do Conselho Estadual de Educação da Guanabara fica evidenciada nas cláusulas que se tornaram permanentes nas leis posteriores que vão instituir e regulamentar o CEE/RJ. É do artigo $2^{\circ}$ da Lei $n^{\circ} 151 / 1962$ (GUANABARA, 1962) que se origina a prerrogativa, incansavelmente reiterada nas regulamentações relativas ao $\mathrm{CEE} / \mathrm{RJ}$, de que as funções de conselheiro são consideradas de "interesse relevante" e que o "seu exercício tem prioridade sobre os de quaisquer cargos públicos de que sejam titulares os conselheiros", ainda que essa disposição não tenha se tornado uma preocupação para grande parte dos conselheiros, detentores de outros cargos públicos. É também da Lei n $151 / 1962$, que surge a ideia de gratificação pela presença, o denominado jeton, a que os 
conselheiros têm "direito" até hoje. Quanto às atribuições, observa-se a atualidade das incumbências previstas para o $\mathrm{CEE} / \mathrm{GB}$, entre elas o acompanhamento, elaboração e execução do plano anual de educação e a emissão de parecer sobre "assuntos e questões de natureza pedagógica e educativa que lhe forem submetidas" (GUANABARA, 1962, Art. $3^{\circ}$ ). Por outro lado, a incumbência de decisão sobre o funcionamento de escolas da rede pública e privada não estava prescrita para este $\mathrm{CEE} / \mathrm{GB}$, sendo uma herança das atribuições previstas pela Lei $\mathrm{n}^{\circ}$ 5.044/1962 (RIO DE JANEIRO, 1962) para o Conselho Estadual de Educação do antigo Estado do Rio de Janeiro.

Grosso modo, a leitura das legislações referentes aos Conselhos de Educação instituídos nos dois Estados existentes antes da fusão demonstra que foram reunidas incumbências de um e outro colegiado, bem como se buscou regimentar práticas consideradas exitosas nos órgãos de origem. O "novo" Conselho resultante da fusão dos dois Estados foi, portanto, herdeiro das incumbências dos Conselhos anteriores, ampliando e complexificando a estrutura e as atribuições do colegiado, delineando a formatação básica que vai perdurar até o presente, originária do Decreto-Lei n ${ }^{\circ}$ 51/1975 (RIO DE JANEIRO, 1975), que criou o CEE/RJ, cujos signatários são o governador Faria Lima e seus dirigentes da educação no Estado, Myrthes de Luca Wenzel e Ronaldo Costa Couto.

Cabe destacar que, guardadas as proporções da nomenclatura que foi sendo atualizada de acordo com as leis federais que estabeleceram as diretrizes educacionais, ao longo dos 42 anos de existência do CEE/RJ, muito se reconhece do Decreto-Lei ${ }^{\circ}$ 51/1975 (RIO DE JANEIRO, 1975) na legislação e nas práticas em vigor no órgão colegiado, especialmente, no que diz respeito à estrutura básica da presidência, assessorias, serviços, divisão em câmaras e comissões, além da imposição de homologação dos resultados dos processos, pareceres e deliberações pelo secretário de Estado de Educação, realizada até bem pouco tempo, já instituída a condição do CEE/RJ como órgão de Estado, pela Lei $\mathrm{n}^{\circ} 6.864 / 2014$ (RIO DE JANEIRO, 2014). Tal fato ocorria não só pela ausência de uma assessoria jurídica própria, mas também pela dificuldade de executar procedimentos burocráticos sem precedentes.

Na contramão da conservação dos princípios do Decreto-Lei n ${ }^{\circ}$ 51/1975 (RIO DE JANEIRO, 1975), chama atenção que o Conselho de Educação do governador Faria Lima, embora subordinado ao secretário de Estado de Educação, fosse caracterizado como unidade orçamentária e administrativa da Secretaria de Estado de Educação e Cultura, condição essa que foi aparecendo e desaparecendo nas alterações dos anos subsequentes, voltando novamente a surgir apenas como 
consequência da elevação a órgão de Estado, ainda que o primeiro orçamento votado pela Assembleia Legislativa do Estado do Rio de Janeiro (Alerj), em 2016, esteja longe das necessidades do órgão e de sua liberação para a execução financeira.

\section{Trajetória legal e representativa do CEE/RJ: a descontinuidade nos governos}

O Decreto-Lei $n^{\circ}$ 51/1975, de criação do CEE/RJ, foi referenciado e alterado muitas vezes antes de sua revogação, que somente vai ocorrer pela Lei ${ }^{\circ} 1.590$, de 18 de dezembro de 1989 (RIO DE JANEIRO, 1989a). Ainda em 1975, modificavam-se, por Decretos posteriores, funções do Conselho, valor do jeton, composição e atribuições das câmaras, comissões, vice-presidência etc. O primeiro Regimento do CEE/RJ, naquele momento tratado pela sigla Cederj ${ }^{5}$, é datado de 31 de março de 1977 e instituído pela Resolução n ${ }^{\circ} 72$, da secretária de Estado de Educação e Cultura, Myrthes Wenzel (RIO DE JANEIRO, 1977). Quatro anos depois, o secretário Arnaldo Niskier, que sucedeu Myrthes Wenzel, já no governo Chagas Freitas, reformula o Regimento do CEE/RJ, por meio da Resolução n ${ }^{\circ}$ 392, de 26 de maio de 1981 (RIO DE JANEIRO, 1981). A diferença mais significativa entre os Regimentos de 1977 e de 1981 é que, enquanto no regulamento da secretária Myrthes Wenzel a presidência e a vice-presidência eram exercidas por conselheiros eleitos por seus pares, no de Arnaldo Niskier, a presidência passou a ser exercida pelo próprio secretário. Além da implantação dos Regimentos de 1977 e 1981, alterações pontuais são feitas no CEE/RJ, por meio de leis e decretos, em 1979, 1980, 1981 e 1982.

Em 15 de março de 1983 toma posse o governador eleito Leonel Brizola e o Estado do Rio de Janeiro passa a ser conduzido por outro grupo político. Ao final do primeiro ano de seu governo, em 24 de novembro de 1983, aludindo ao que restava sem alterações do Decreto-Lei do governador Faria Lima e fazendo cinco longas considerações que justificavam a medida, o CEE/RJ sofre uma reestruturação, pelo Decreto $\mathrm{n}^{\circ} 6.911$ (RIO DE JANEIRO, 1983), assinado pelo próprio governador Leonel Brizola, pela secretária de Estado de Educação Yara Lopes Vargas e por Darcy Ribeiro vice-governador, no qual são considerados extintos todos os mandatos de conselheiros, tendo como base argumentativa a não observação da periodicidade de renovação escalonada prevista no Decreto-Lei $n^{\circ}$ 51/1975 (RIO DE JANEIRO, 1975), destituindo-se titulares e suplentes e legitimando a nomeação pela secretária de Estado de Educação de novos membros.

\footnotetext{
O primeiro Regimento do Conselho Estadual de Educação do Rio de Janeiro instituído pela Resolução n 72, de 31 de março de 1977 (RIO DE JANEIRO, 1977), apresenta no Título I, Artigo 1², a sigla Cederj, que vai permanecer designando o órgão até o último Regimento, aprovado pela Resolução $\mathrm{n}^{\circ} 1.348$, de 07 de outubro de 1986.
} 
Vale notar que embora a medida visasse claramente "mudar de mãos" a condução da educação fluminense, aproveitando-se a euforia da eleição e promessas de realizações do primeiro governo de Leonel Brizola no Rio de Janeiro, a composição do Conselho nomeado por ele, permaneceu com alguns dos membros destituídos do mandato no colegiado anterior, ainda que apareçam como conselheiros novos atores no cenário educacional, que serão protagonistas na implantação de políticas educacionais para além daquele governo.

Também no governo de Leonel Brizola, sendo secretária Maria Yedda Leite Linhares, é estabelecido um novo Regimento para o CEE/RJ, pela Resolução $\mathrm{n}^{\circ} 348$, de 07 de outubro de 1986 (RIO DE JANEIRO, 1986), que se reportava, ainda, ao Decreto-Lei n ${ }^{\circ}$ 51/1975 (RIO DE JANEIRO, 1975). Compete destacar a vigência longeva desse regulamento, que se perpetua até adiantado o ano de 2017, enquanto o CEE/RJ não havia concluído as discussões sobre um novo Regimento, que incorporasse também sua natureza e incumbências como órgão de Estado.

Ao assumir o governo em 1987, o governador Moreira Franco procede da mesma forma que seu antecessor, com a diferença de ter tomado essa atitude no início do mês de maio, ou seja, com poucos meses de exercício, extinguindo os mandatos de todos os conselheiros titulares e suplentes, embora sem a preocupação de fazer detalhadas considerações para justificar a medida tomada. Pelo Decreto $\mathrm{n}^{\circ}$ 9.916, de 05 de maio de 1987 (RIO DE JANEIRO, 1987), com somente dois artigos, no primeiro ele extinguia todos os mandatos e no segundo determinava que o secretário de Estado de Educação, Carlos Alberto Menezes Direito, também signatário do documento, indicasse ao governador, novos conselheiros.

Em maio de 1988, exatamente um ano depois do Decreto $n^{\circ}$ 9.916/1987 (RIO DE JANEIRO, 1987), o governador Moreira Franco, por meio do Decreto $\mathrm{n}^{\circ}$ 11.296, de 13 de maio de 1988 (RIO DE JANEIRO, 1988), extingue, novamente, os mandatos dos conselheiros e designa novos membros para compor o colegiado, no corpo do mesmo diploma legal. Chamam atenção as considerações que introduzem o Decreto ${ }^{\circ} 11.296 / 1988$, pois sugerem que havia graves problemas relacionados ao $\mathrm{CEE} / \mathrm{RJ}$, a ponto de ser lembrado "o clima de ordem e respeito pela coisa pública", que deveriam ser observados, além da afirmação de que teriam sido adotados neste órgão, critérios que geraram "desencontros, inconformismos nas camadas da população", instalando "um ambiente de incompreensão e animosidade", dificultando o poder do Estado de "polícia administrativa" (RIO DE JANEIRO, 1988, p. 2). A solução encontrada 
pelo chefe do executivo, nas palavras do próprio Decreto, foi destituir todo o Conselho e nomear novos membros.

Embora sozinhos os documentos legais não sejam capazes de recompor uma história, o que se depreende da análise desse material, é que se tratava de um período extremamente conturbado em relação à política educacional no Estado, evidenciado no $\mathrm{CEE} / \mathrm{RJ}$ pelo elevado número de conselheiros que, em algum momento, tiveram mandato, durante os quatro anos, entre 1987 e 1990 . A Revista Rio Educação (RIO DE JANEIRO, 2015, p. 46-48) lista 78 conselheiros titulares e 15 suplentes como membros do CEE/RJ, durante o governo de Moreira Franco. Para se avaliar o significado desse quantitativo, é preciso compará-lo com os demais governos anteriores e subsequentes, verificando-se que, com exceção deste período, o maior número de conselheiros designados ao longo dos quatro anos de todos os governos do pós-fusão, é de 39 titulares de mandatos no CEE/RJ, registrado anos de 2007 a 2010, durante o governo de Sérgio Cabral (RIO DE JANEIRO, 2015, p. 56).

A análise do quantitativo de conselheiros ao longo dos anos de 1987 a 1990 demonstra que o CEE/RJ passou por, pelo menos, três extinções de mandatos dos 21 conselheiros que compõe o colegiado. Tal fato é confirmado pelas fontes documentais, pois além das extinções de mandatos realizadas pelos decretos já citados de 1987 e 1988, em 8 de novembro de 1989, o governador Moreira Franco, por meio do Decreto $n^{\circ} 13.838$ (RIO DE JANEIRO, 1989b), reestrutura o CEE/RJ e extingue, mais uma vez, os mandatos dos conselheiros, registrando nas considerações iniciais do diploma legal (RIO DE JANEIRO, 1989b), que as medidas se deviam, à "recém-promulgada Constituição do Estado do Rio de Janeiro", que mencionava o Conselho e a competência desse órgão para fixar os preços das mensalidades escolares nas escolas particulares, devendo coibir aumentos excessivos, entre outras alusões. Logo a seguir, no mesmo ano, 1989, é publicada a Lei n ${ }^{\circ} 1.590$, de 18 de dezembro (RIO DE JANEIRO, 1989a), sancionada pelo governador, na qual eram, outra vez, estabelecidas as atribuições e composição do Conselho. Nesta Lei ficava determinado que o CEE/RJ "integra a estrutura básica da Secretaria de Estado de Educação, da qual constitui unidade orçamentária e administrativa", além disso, o número de conselheiros era ampliado para 24 membros, distribuídos entre 18 indicações de livre escolha do governador, dois representantes de usuários e dois representantes de trabalhadores do ensino. Além disso, o secretário de Estado de Educação continuava na presidência do CEE/RJ como membro nato. Enfim, 14 anos depois, era revogado o Decreto-Lei no 51/1975 (RIO DE JANEIRO, 1975) e as demais disposições contrárias à nova Lei. 
Em 1991, Leonel Brizola é eleito para o seu segundo governo no Rio de Janeiro. Assim que toma posse, em 15 de março, trata, mais uma vez, de desfazer o colegiado do CEE/RJ e pelo Decreto $\mathrm{n}^{\circ} 16.553$, de 18 de abril de 1991, extingue os mandatos de todos os conselheiros, determinando que até a "nova composição do Conselho, a Secretária de Estado de Educação responderá, no que for pertinente, pelo expediente administrativo daquele órgão consultivo" (RIO DE JANEIRO, 1991, Art. $2^{\circ}$ ). Dessa vez, não há preocupação em fazer considerações e, em apenas dois artigos, todo o colegiado é destituído. O Conselho não foi recomposto imediatamente e um espaço de quase um ano de interrupção no funcionamento do órgão marcou profundamente essa época. Por outro lado, novos acontecimentos significativos viriam, também, identificar esse período.

Os anos de 1990 foram marcados pela expectativa da "nova" LDBEN (BRASIL, 1996), e, após sua publicação, por tentativas do colegiado do CEE/RJ de entender seus princípios que diferiam, sobremaneira, de sua antecessora a Lei ${ }^{\circ} 5.692$, de 11 de agosto de 1971 (BRASIL, 1971), com a qual os conselheiros subsidiavam seu trabalho há 25 anos. Somava-se a isso, um processo já iniciado antes da nova LDBEN, instigado pelo disposto na Constituição de 1988 (BRASIL, 1988), que concedia autonomia aos municípios para criarem seus próprios sistemas de ensino, tendo o $\mathrm{CEE} / \mathrm{RJ}$ tomado para si o protagonismo do cumprimento da medida, como a instância preparadora dos municípios para o encaminhamento de ações locais com essa finalidade. De acordo com Vasconcelos e Souza (2008, p. 189), "as cartas legais emanadas do Conselho Estadual de Educação constituíram-se instrumentos fundamentais para os municípios se organizarem como sistemas de ensino, assumindo as responsabilidades e competências da gestão da educação municipal".

É também nesse período que o Conselho Nacional de Educação (CNE), criado a partir da Lei n ${ }^{\circ}$ 9.131, de 24 de novembro de 1995 (BRASIL, 1995), afirma-se como um órgão de Estado, tendo em vista que sua composição era baseada em critérios explícitos de representação dos diversos setores e entidades educacionais, embora a lista fosse apresentada ao ministro da Educação, que escolhia os conselheiros para um mandato de quatro anos, respeitando essa integralidade ${ }^{6}$. Enquanto isso, grande parte dos CEEs, permaneciam como órgãos de governo, com os conselheiros escolhidos exclusivamente por suas relações políticas, sujeitando-se também às interrupções de mandatos, que ocorriam quando era mudada a condução da gestão governamental.

\footnotetext{
6 Essa situação foi alterada pelo Decreto SN de 27, de junho de 2016, quando o presidente em exercício Michel Temer, tornou sem efeito as nomeações publicadas em maio de 2016, pela então presidente Dilma Rousseff, nomeando outros conselheiros para as vagas existentes.
} 
No CEE/RJ, após quase uma década de manutenção da mesma regulamentação, a Lei ${ }^{\circ}$ 1.590/1989 (RIO DE JANEIRO, 1989a), com o advento da nova LDBEN, Marcelo Alencar, nos últimos dias de seu governo, sanciona a Lei $\mathrm{n}^{\circ} 3.155$, de 29 de dezembro de 1998, que "autorizava o poder executivo a dispor sobre a reformulação do Conselho Estadual de Educação" (RIO DE JANEIRO, 1998). Como o próprio texto da Lei já se encarregava de estabelecer a natureza, as finalidades, a composição (que volta a ser de 21 membros), as funções dos conselheiros, a estrutura básica do órgão, além das atribuições da presidência, secretaria, assessorias, câmaras e comissões, restava muito pouco para o poder executivo determinar, e nada foi feito neste sentido, pelos governos subsequentes de Anthony Garotinho e Benedita da Silva. A Lei permaneceu sem alterações até o ano de 2004, quando a governadora Rosinha Garotinho, por meio da Lei $\mathrm{n}^{\circ} 4.301$, de 26 de março (RIO DE JANEIRO, 2004), apenas corrige um erro de redação relativo à recondução dos mandatos dos conselheiros. Em todos os outros pontos, a Lei $n^{\circ} 3.155 / 1998$ (RIO DE JANEIRO, 1998), permaneceu vigorando, incluindo-se a distribuição das 21 vagas de conselheiros, entre oito membros de livre escolha do governador, oito membros indicados pela Alerj, homologados pelo governador, e cinco membros representantes de órgãos de classe ou associações da área de educação, designadas no artigo $7^{\circ}$ como sendo o Sindicato dos Professores do Ensino Particular; o Sindicato dos Estabelecimentos Particulares de Ensino; a Associação ou Sindicato dos Professores Públicos do Estado do Rio de Janeiro; a Associação de Pais e Responsáveis do Estado do Rio de Janeiro; e a União Estadual de Secretários Municipais de Educação.

Em 2005, por iniciativa da Alerj, é instituída a Lei no 4.528, de 28 de março (RIO DE JANEIRO, 2005), que estabelecia as diretrizes para a organização do sistema de ensino do Estado do Rio de Janeiro. Essa Lei em seu texto original possuía um capítulo com cinco artigos referentes ao CEE/RJ, no sentido de torná-lo mais autônomo e representativo. Contudo, três artigos, foram integralmente vetados pela governadora Rosinha Garotinho, permanecendo no texto legal somente o artigo $9^{\circ}$ que caracterizava o Conselho como órgão da Secretaria de Educação e o artigo 12 que determinava a escolha do presidente e vice-presidente do órgão pelo governador, por meio de lista tríplice enviada após escrutínio secreto entre os membros do colegiado. No mais, a governadora optou por deixar vigentes as determinações da Lei ${ }^{\circ}$ 3.155/1998 (RIO DE JANEIRO, 1998) do governo Marcelo Alencar.

Ao longo dos governos do Estado do Rio de Janeiro nos anos 2000, o CEE/RJ sofreu constantes perdas materiais e humanas, tanto reduzindo e deteriorando o seu espaço físico, como não havendo substituição de funcionários que se 
aposentavam e levavam consigo uma considerável experiência nas rotinas do órgão, mas cuja multiplicação desses conhecimentos não foi sequer cogitada.

Ao findar a década de 2000, estão registradas em diferentes Atas das sessões plenárias, manifestações do colegiado, sinalizando que o Conselho perdia sua representatividade, não apenas como consequência da descontinuidade de planejamento dos governos para esse órgão, constatada em toda a sua trajetória, mas, também, porque suas ações se voltavam, cada vez mais, para a rede privada, sendo, o CEE/RJ, por vezes, ignorado pelos setores públicos que faziam parte do sistema estadual de ensino, em que pese alguns de seus representantes serem membros do Conselho.

A análise da trajetória do CEE/RJ, especialmente de seus marcos legais, remete ao questionamento proposto por Calderón (2008, p. 177), "ante uma cultura política centralizadora e patrimonialista, convém questionar: até que ponto seria viável atingir a governabilidade, considerando os conselhos como novas instâncias que limitam o exercício da função governativa?". A elevação do CEE/RJ a órgão de Estado oferece algumas respostas.

\section{Finalizando: o que mudou no CEE/RJ com a elevação a órgão de Estado?}

A trajetória do $\mathrm{CEE} / \mathrm{RJ}$ está eivada de constante interferência política, tanto na configuração do órgão como na composição do colegiado, pois, não há outra forma de ser indicado conselheiro, excetuando-se as representações classistas, senão pela via das indicações do governador ou da Alerj. Além disso, trata-se de um colegiado extremamente disputado, uma vez que, como afirma Gohn (2008), ocupar espaços nos conselhos pode ser uma maneira de estar presente em arenas nas quais decisões importantes são tomadas, acessível a poucos e não necessariamente somente "possuidores de notável saber na área educacional ou que tenham prestado relevantes serviços à educação" (RIO DE JANEIRO, 2014, Art. 5).

Embora tenha sido elevado à condição de órgão de Estado pela Lei n ${ }^{\circ}$ 6.864/2014 (RIO DE JANEIRO, 2014), até o presente, nada garante no texto desta legislação ou de qualquer outra que a normatize, que os mandatos dos conselheiros não possam ser interrompidos, bem como que sejam observados critérios ou listas de entidades para as indicações do poder executivo e legislativo.

De forma antagônica, sua desvinculação da Secretaria de Estado de Educação, não tornou o $\mathrm{CEE} / \mathrm{RJ}$ mais autônomo, ainda que mais próximo do governo 
central e de suas determinações diretas. Notadamente, manteve-se a prática de ouvir o secretário de Estado de Educação, tanto na composição do colegiado, como em qualquer assunto que diga respeito ao órgão normativo da educação fluminense. Além disso, todos os funcionários lotados no CEE/RJ são, majoritariamente, pertencentes aos quadros dessa Secretaria, bem como ela fornece os mecanismos básicos para o seu funcionamento, sem os quais é inviabilizada qualquer ação.

Cabe ressaltar que logo após a publicação da Lei $n^{\circ}$ 6.864/2014 (RIO DE JANEIRO, 2014), uma das mudanças mais significativamente sentidas no $\mathrm{CEE} / \mathrm{RJ}$ foi o despejo das instalações da antiga sala de sessões plenárias, usada desde a instalação do primeiro colegiado, para acomodar outro setor do governo. Por sua vez, o mobiliário, que remontava também à instalação do órgão, com cadeiras pesadas e de alturas diferenciadas para marcar a hierarquia imponente de seus membros, foi transladado para uma pequena sala, na qual contrastam expressivamente não só o espaço, a arquitetura e o mobiliário, mas o simbolismo que se depreende dessa mudança.

Para entender a natureza do CEE/RJ, hoje, talvez, seja preciso algumas aproximações com o que afirma Bobbio, ao preconizar que "ao longo de toda a história o debate secular sobre a razão do Estado" esteve "ao lado da justificação da 'imoralidade' da política” (BOBBIO, 2000, p.189). Assim, por vezes, é preciso recorrer à impessoalidade e à isenção do Estado para fazer frente às descontinuidades político-partidárias que, periodicamente, desconstroem projetos, programas e até instituições.

Estendendo-se para além do objeto deste estudo e examinando a dinâmica dos Conselhos em outros estados, nota-se que os movimentos e as rupturas com forte conotação política que estão presentes na trajetória do CEE/RJ, não são um privilégio da configuração deste órgão normativo, mas aparecem, continuamente, nas instâncias colegiadas da educação em outros entes federados. Pesquisadores que se debruçaram sobre Conselhos de Educação da região Sudeste, por exemplo, constataram, em diferentes momentos, a mesma interferência dos governos e semelhantes desafios para sobrepujar práticas intervencionistas e tendências hegemônicas de tradição centralista, que impõe aos colegiados uma "participação regulada" (FERREIRA; FERREIRA, 2013; MARTINS et al., 2013; DUARTE; OLIVEIRA et al., 2013).

Apesar da inegável importância de tornar o CEE/RJ, legalmente, um órgão de Estado, a ênfase dada a esse "novo modelo de gestão" expõe um "velho modelo" 
de Conselho (PEIXOTO, 2012, p.2 28). Aos pesquisadores que investigam o $\mathrm{CEE} / \mathrm{RJ}$, sobressaem evidências de que alguns aspectos positivos legados dos Conselhos do antigo Estado do Rio de Janeiro e do Estado da Guanabara se dissiparam, restando aqueles que, contrariamente, deveriam ter sido superados, como no dizer de Souza e Vasconcelos (2006, p. 51), "o comprometimento da independência dos conselheiros e da autonomia do órgão". Conclui-se que a trajetória do colegiado é profundamente marcada pela descontinuidade de políticas específicas para este setor normativo, fazendo com que a condição de órgão de Estado seja imperceptível no cotidiano e nas proposições que, hoje, regem a educação fluminense. 


\section{Education Council of the state of Rio de Janeiro: inheritances, legal landmarks and political limits of a state organ}

\section{Abstract}

The present study aims to analyze the trajectory of the Education Council of the state of Rio de Janeiro (CEE/RJ), especially the "inheritances" and influences of the collegiate bodies that originated it, and the legal landmarks that had the greatest impact on its history. This, in a temporal demarcation that goes from the law that created it, Decree Law n. 51/1975, until the Law that made it a state organ, Law n. 6.864/2014. In a more specific level, the implications that governmental changes produced in the collegiate body, carried out by the actors of the political context in which the CEE/RJ was inserted, are also evidenced. This is a bibliographical and essentially documentary research that shows, with subsidies from the sources, how the CEE/RJ was marked by the discontinuity in politics, that made that its condition of state organ is currently almost imperceptible in the meetings and deliberations of the collegiate body that regulate the education of the state of Rio de Janeiro.

Keywords: State Council of Education. State Organ. Educational policies. Rio de Janeiro.

\section{Consejo de Educación del estado de Rio de Janeiro: herencia, marcos legales y límites políticos de un órgano del estado}

\section{Resumen}

Este estudio se centra en el análisis de la trayectoria del Consejo de Educación del estado de Río de Janeiro (CEE/RJ), en particular la "herencia" e influencia de los colegialiados que lo originaron, y los marcos legales que tuvieron el mayor impacto en su historia, en una demarcación temporal que se extiende desde la primera ley de su creación, el Decreto Ley $n^{\circ} 51 / 1975$, y la Ley $n^{\circ} 6.864 / 2014$, que lo convritió en órgano del estado. En un plan más especifico, se trató de poner de relieve las implicaciones que los cambios de gobierno han producido en el colegiado, protagonizados por los actores del contexto político en el que se inserta el CEE/RJ. Se trata de una investigación esencialmente bibliográfica documental que muestra, con subsidios de las fuentes, cómo el CEE/RJ estuvo marcado por la discontinuidad en la política, haciendo que la condición de órgano de estado no sea notable en la vida cotidiana y en las proposiciones del colegiado que, hoy, rigen la educación fluminense.

Palabras clave: Consejo de Educación del Estado. Órgano del Estado. Las políticas educativas. Rio de Janeiro. 


\section{Referências}

BOBBIO, N. Teoria geral da política: a filosofia política e as lições dos clássicos. Rio de Janeiro: Campus, 2000.

BRASIL. Decreto SN de 27 de junho de 2016. Torna sem efeito os Decretos de 10 de maio de 2016, publicados no Diário Oficial da União do dia 11 de maio de 2016, Seção 2, página 1, referentes aos membros indicados para comporem as Câmaras do Conselho Nacional de Educação.. Diário Oficial da União, Brasília, DF, 27 jun. 2016.

. Lei $\mathrm{n}^{\circ} 4.024$, de 20 de dezembro de 1961. Fixa as diretrizes e bases da educação nacional. Diário Oficial da União, Brasília, DF, 27 dez. 1961.

. Lei $\mathrm{n}^{\circ} 5.692$, de 11 de agosto de 1971. Fixa Diretrizes e Bases para o Ensino de $1^{\circ}$ e $2^{\circ}$ graus, e dá outras providências. Diário Oficial da União, Brasília, DF, 12 ago. 1971.

. Constituição (1988). Constituição da República Federativa do Brasil. Diário Oficial da União, Brasília, DF, 5 out. 1988.

. Lei ${ }^{\circ}$ 9.131, de 24 de novembro de 1995. Altera dispositivos da Lei $\mathrm{n}^{\circ} 4.024$, de 20 de dezembro de 1961, e dá outras providências. Diário Oficial da União, Brasília, DF, 25 nov. 1995.

. Lei $\mathrm{n}^{\circ} 9.394$, de 20 de dezembro de 1996. Estabelece as diretrizes e bases da educação nacional. Diário Oficial da União, Brasília, DF, 23 dez. 1996.

CALDERÓN, A. Conselhos municipais: representação, cooptação e modernização da política patrimonialista. In: SOUZA, D. B. (Org.). Conselhos municipais e controle social da educação: descentralização, participação e cidadania. São Paulo: Xamã, 2008. p.169-90.

DUARTE, M. R. T.; OLIVEIRA, R. F. CMEs no estado de Minas Gerais: das funções atribuídas no regime de colaboração. In: SOUZA, D. B. (Org.). Mapa dos Conselhos Municipais de Educação no Brasil. São Paulo: Loyola, 2013. p. 165-85.

FERREIRA, M. M. A fusão do Rio de Janeiro, a ditadura militar e a transição política. In: ABREU, A. A. (Org.). A democratização do Brasil: atores e contextos. Rio de Janeiro: FGV, 2006. p. 163-203.

FERREIRA, E. B.; FERREIRA, A. A. CMEs no estado do Espírito Santo: a participação regulada. In: SOUZA, D. B. (Org.). Mapa dos Conselhos Municipais de Educação no Brasil. São Paulo: Loyola, 2013. p. 111-28. 
GOHN, M. G. Conselhos municipais de acompanhamento e controle social em Educação: participação, cidadania e descentralização? In: SOUZA, D. B. (Org.). Conselhos municipais e controle social da educação: descentralização, participação e cidadania. São Paulo: Xamã, 2008. p. 97-114.

GUANABARA (Estado). Constituição do Estado da Guanabara, de 27 de março de 1961. Rio de Janeiro: Imprensa Nacional, 1961.

. Lei $\mathrm{n}^{\circ} 151$, de 13 de julho de 1962. Cria o Conselho Estadual de Educação e dá outras providências. Diário Oficial do Estado da Guanabara, Rio de Janeiro, 10 jul. 1962.

MARTINS, A. M.; OLIVEIRA, C.; PIMENTA, C. O. CMEs no estado de São Paulo: uma análise de órgãos colegiados em municípios paulistas. In: SOUZA, D. B. (Org.). Mapa dos Conselhos Municipais de Educação no Brasil. São Paulo: Loyola, 2013. p. 149-64.

OLIVEIRA, C. et al. Conselhos Municipais de Educação: um estudo na região metropolitana de Campinas. Campinas: Alínea, 2006.

OZGA, J. Investigações sobre políticas educacionais. Porto: Porto, 2000.

PEIXOTO, L. CME de Nova Iguaçu. In: VALLE, B. B. R.; VASCONCELOS, M. C. C. (Orgs.). Conselhos Municipais de Educação: organização e atribuições nos sistemas de ensino do Estado do Rio de Janeiro. Rio de Janeiro: Quartet, Faperj, 2012. p. 219-31.

RIO DE JANEIRO (Estado). Conselho Estadual de Educação. Normas do Conselho Estadual de Educação: deliberações 2004/2015, pareceres normativos 2004/2015. Rio Educação, n ${ }^{\circ}$ esp. 9, 2015.

. Decreto-Lei n ${ }^{\circ}$ 1, de 15 de março de 1975. Estabelece a organização básica do Estado do Rio de Janeiro e dá outras providências. Diário Oficial do Estado do Rio de Janeiro, Rio de Janeiro, 16 mar. 1975.

. Decreto Lei $\mathrm{n}^{\circ}$ 51, de 03 de abril de 1975. Cria o Conselho Estadual de Educação do Rio de Janeiro, dispõe sobre sua natureza, finalidade, composição, estrutura e competência básica e dá outras providências. Diário Oficial do Estado do Rio de Janeiro, Rio de Janeiro, 9 abr. 1975.

. Decreto ${ }^{0} 6.911$, de 24 de novembro de 1983. Reestrutura o Conselho Estadual de Educação. Diário Oficial do Estado do Rio de Janeiro, Rio de Janeiro, 25 nov. 1983. 
RIO DE JANEIRO (Estado). Decreto $\mathrm{n}^{\circ}$ 9.916, de 05 de maio de 1987. Dispõe sobre o Conselho Estadual de Cultura e Conselho Estadual de Educação. Diário Oficial do Estado do Rio de Janeiro, Rio de Janeiro, 6 mai. 1987.

. Decreto $\mathrm{n}^{\mathrm{o}} 11.296$, de 13 de maio de 1988. Dispõe sobre o Conselho Estadual de Educação. Diário Oficial do Estado do Rio de Janeiro, Rio de Janeiro, 16 mai. 1988.

. Decreto $\mathrm{n}^{\mathrm{o}} 13.838$, de 8 de novembro de 1989. Reestrutura o Conselho Estadual de Educação. Diário Oficial do Estado do Rio de Janeiro, Rio de Janeiro, 8 nov. 1989b.

. Decreto $\mathrm{n}^{\mathrm{o}} 16.553$, de 18 de abril de 1991. Considera extinto o mandato dos membros do Conselho Estadual de Educação. Diário Oficial do Estado do Rio de Janeiro, Rio de Janeiro, 19 abr.1991.

. Lei ${ }^{\circ} 1.590$, de 18 de dezembro de 1989. Estabelece as atribuições do Conselho Estadual de Educação. Diário Oficial do Estado do Rio de Janeiro, Rio de Janeiro, 18 dez. 1989a.

. Lei $\mathrm{n}^{\mathrm{O}} 3.155$, de 29 de dezembro de 1998. Autoriza o poder executivo a dispor sobre a reformulação do Conselho Estadual de Educação. Diário Oficial do Estado do Rio de Janeiro, Rio de Janeiro, 29 dez. 1998.

. Lei ${ }^{\circ} 4.301$, de 26 de março de 2004. Altera a redação do art. $3^{\circ}$ da Lei n ${ }^{\circ} 3.155$, de 29 de dezembro de 1998. Diário Oficial do Estado do Rio de Janeiro, Rio de Janeiro, 29 mar. 2004.

. Lei $\mathrm{n}^{\circ} 4.528$, de 28 de março de 2005. Estabelece as diretrizes para a organização do Sistema Estadual de Ensino do Rio de Janeiro. Diário Oficial do Estado do Rio de Janeiro, Rio de Janeiro, 12 ago. 2005.

. Lei $\mathrm{n}^{\circ}$ 5.044, de 07 de março de 1962. Estabelece as Diretrizes e Bases Estaduais da Educação. Diário Oficial do Estado do Rio de Janeiro, Rio de Janeiro, 10 jun. 1962.

. Lei $\mathrm{n}^{\mathrm{0}} 6.864$, de 15 de agosto de 2014. Altera dispositivo da Lei $\mathrm{n}^{\circ} 4.528$, de 28 de março de 2005. Diário Oficial do Estado do Rio de Janeiro, Rio de Janeiro, 15 ago. 2014.

. Resolução $\mathrm{n}^{\circ} 72$, de 31 de março de 1977. Aprova o regimento do Conselho Estadual de Educação do Rio de janeiro. Diário Oficial do Estado do Rio de Janeiro, Rio de Janeiro, 4 abr. 1977. 
RIO DE JANEIRO (Estado). Resolução n ${ }^{0} 348$, de 07 de outubro de 1986. Aprova a reformulação do regimento do Conselho Estadual de Educação do Rio de janeiro. Diário Oficial do Estado do Rio de Janeiro, Rio de Janeiro, 10 out. 1986.

. Resolução ${ }^{0} 392$, de 26 de maio de 1981. Reformula o regimento do Conselho Estadual de Educação do Rio de Janeiro. Diário Oficial do Estado do Rio de Janeiro, Rio de Janeiro, 28 mai. 1981.

SOUZA, D. B.; \& VASCONCELOS, M. C. C. Os Conselhos Municipais de Educação no Brasil: um balanço das referências nacionais (1996-2002). Ensaio: Avaliação e Políticas Públicas em Educação, v. 14, n. 50, p. 39-56, jan./mar. 2006. https://doi.org/10.1590/S0104-40362006000100004

VASCONCELOS, M. C. C.; SOUZA, R. P. As políticas de municipalização do ensino no Estado do Rio de Janeiro. In: FARIA, L. C. M.; SOUZA, S. C. (Orgs.). Ecos e memórias de escola fluminense. Rio de Janeiro: Quartet, Faperj, 2008. p. 45-67.

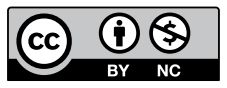

\section{Informações dos autores}

Maria Celi Chaves Vasconcelos: Professora doutora. Professora associada do Programa de Pós-graduação em Educação e Chefe do Departamento de Políticas Públicas, Avaliação e Gestão da Educação da Universidade do Estado do Rio de Janeiro (ProPEd/UERJ). Membro do Conselho Estadual de Educação (CEE/RJ). Pós-doutora em Educação pela Universidade do Minho, Portugal. Bolsista de Produtividade do Conselho Nacional de Desenvolvimento Científico e Tecnológico (CNPq) e Procientista (UERJ). Contato: maria2.celi@gmail.com

Nival Nunes Almeida: Professor doutor. Professor titular da Escola de Guerra Naval da Marinha do Brasil (EGN/MB) e Membro do Programa de Pós-graduação em Estudos Marítimos (PPGEM/EGN). Professor do Programa de Pós-graduação em Engenharia Eletrônica da Universidade do Estado do Rio de Janeiro (PEL/UERJ). Membro do Conselho Estadual de Educação do Rio de Janeiro (CEE/RJ) nos anos de 2005 a 2013. Contato: nivalnunes@yahoo.com.br

Leonardo Ferreira Peixoto: Professor mestre. Professor Assistente do Centro de Estudos Superiores de Tabatinga da Universidade do Estado do Amazonas (UEA). Estudante do Curso de Doutorado em Educação do Programa de Pós-Graduação em Educação (ProPEd) da Universidade do Estado do Rio de Janeiro (UERJ). Bolsista de Doutorado pela Coordenação de Aperfeiçoamento de Pessoal de Nível Superior (Capes).Contato: leopeixoto.uea@gmail.com 